\title{
Analysis of Multiple Cyanobacteria in Chaohu Lake
}

\author{
Xuan $\mathrm{Hu}$ \\ School of Electrical Engineering, North China Electric Power University, Baoding 071003, China \\ hgdysg2008@qq.com
}

Keywords: Chaohu Lake; algae; Cyanobacteria bloom; Eutrophication.

\begin{abstract}
Cyanobacteria are the most simple and most primitive algae, which bloom in some serious eutrophicative lake. When they form a layer of blue-green bubbles which smell, they are called water blooms. The most typical lakes in China where the cyanobacterial blooms break out are Taihu Lake and Chao Lake. Of the "three rivers and three lakes" which are famous for water pollution, the Chaohu Lake area is the key area for water pollution control. This paper collects relevant data of the amount of algae and the area of water bloom in Chaohu Lake, summarizes the research on the outbreak of algae bloom in the lake, and puts forward feasible suggestions for dealing with cyanobacterial bloom in the lake.
\end{abstract}

\section{Introduction}

Chaohu is located in the southeast of Anhui Province, is one of China's five major freshwater. The area of the lake is $752 \mathrm{~km}^{2}$, the annual rainfall is $1100 \mathrm{~mm}$. Chaohu Lake Basin belongs to the subtropical and warm temperate transition of the subtropical monsoon climate zone, climate mild and humid, moderate rainfall, humidity, monsoon climate significantly. Chaohu Lake is known as "Yumizhixiang" reputation, rich in grain, oil, cotton, hemp, vegetables and fruit crops, depending on the lake and textile, food and other pillar industries.

In twentieth Century 50 's, Chaohu water quality is fine, the mineralization degree is extremely low, the acid base is moderate, the aquatic plants flourish, the biodiversity is rich. In the early 60's, the lake gradually turned into a semi enclosed water body for artificially regulated by the Chaohu gate. As the water conservancy projects changed the ecological environment of the lake, the water quality of the lake is deteriorating. The average water quality of the whole lake is heavily polluted, the total nitrogen and total phosphorus content is seriously over standard, the cyanobacteria every year. The eutrophication of water body is gradually emerging ${ }^{[1]}$.

Anhui Province since 2013 implement blue-green algae warning and emergency special monitoring activities, every year on April 1st to September 30th time by the Hefei Station 10 indicators of the Chaohu 12 lake monitoring of water temperature, $\mathrm{pH}$ value, dissolved oxygen, transparency, ammonia and other, seven indicators of Taihu Lake River water temperature, $\mathrm{pH}$ value, dissolved oxygen, ammonia nitrogen, IMN, etc. to carry out special early warning and emergency response monitoring. Provincial station through satellite remote sensing images, timely analysis of whether the interpretation of cyanobacteria gathered. This paper collects the data ${ }^{[2]}$ from 2015 and April to May,. X. (the maximum and the minimum number of algae, see the second axis).

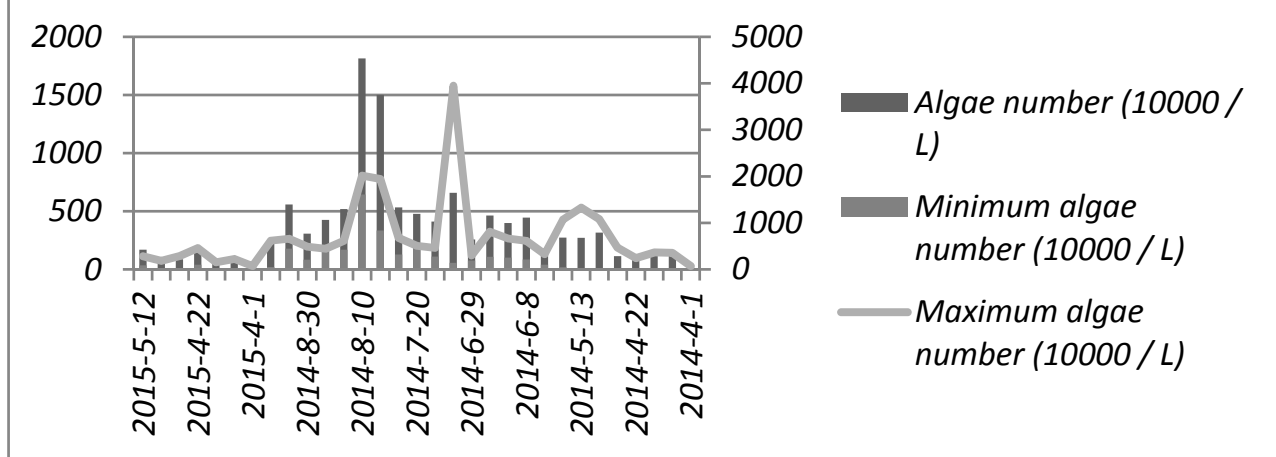

Fig 1. Chaohu algae monitoring data 
From the map line, the annual 7, August is the highest algae, the highest monitoring results appeared in August 10, 2014, each liter of water up to 20192700 algae. The same period in previous years, compared to a relatively stable stage.

According to the relationship between the amount of algae and the degree of water bloom, in table 1. In the statistical data of 31 weeks of time, no obvious bloom weeks for 13 weeks, accounting for all the time $41.93 \%$; slight bloom week for 15 weeks, accounted for $48.39 \%$ of all time; mild bloom weeks for 3 weeks. $(9.68 \%$ of all time.

Table 1. Degree of water bloom grading standards (Provisional)

\begin{tabular}{|c|c|}
\hline Algae number (10000 / L) & Water bloom degree \\
\hline$<2.0 \times 10^{6}$ & No obvious bloom \\
\hline$\geq 2.0 \times 10^{6}$ & Mild bloom \\
\hline$\geq 1.0 \times 10^{7}$ & Light bloom \\
\hline$\geq 5.0 \times 10^{7}$ & Moderate bloom \\
\hline$\geq 1.0 \times 10^{8}$ & Severe bloom \\
\hline
\end{tabular}

According to remote sensing the bloom and area, in accordance with the table of 2014 April 1 to September 21, 2015 April 1 to May 19, data statistics get the bloom size grading standards.

In the monitoring of time all 233 days, cloudless region without obvious bloom belong to no significant bloom, a total of 135 days, accounted for $57.94 \%$; covered by clouds cannot determine the bloom of stay of 25 days, $10.73 \%$; sporadic nature blooms, the number of days to 58 days, accounted for $24.89 \%$; local bloom days for five days, accounting for $2.15 \%$. The most serious water bloom cyanobacteria occurred in August 15, 2014. The water bloom area and the total Lake area were plotted, get the figure 2, and the water bloom area was. (The total Lake area ratio of the total Lake area ratio of the second axis) from the map can be drawn 8 , September water bloom situation is the most serious this conclusion.

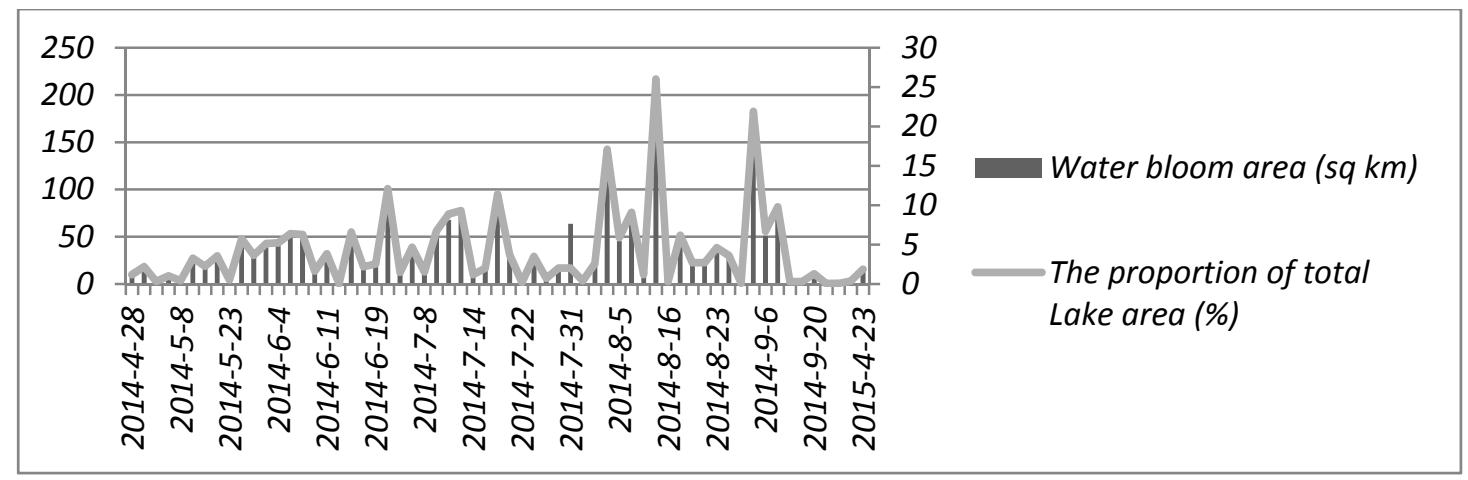

Fig 2. Chaohu water bloom area

\section{Cyanobacteria bloom analysis}

The record of cyanobacteria bloom in Chaohu more than 100 years ago. Local residents commonly known as the phenomenon as "Lake Dian", according to different seasons can be divided into spring indigo (early spring bloom), mycophenolate indigo (late spring bloom), Fu Dian Xia Jishuihua, autumn indigo (autumn bloom). These algae material although it can be used as fertilizer in some crops, but can also be such that people and animals by toxic effects, threatening the human health and destruction of the ecological system of sustainable development. For this phenomenon in the past 80 years of time, different scholars put forward a few ten different hypothesis, similar to: (1) total 
nitrogen / phosphorus ratio hypothesis ${ }^{[3]},(2)$ cell buoyancy hypothesis $\left.{ }^{[4]}, 3\right)$ and high $\mathrm{pH}$ value / high $\mathrm{CO} 2$ hypothesis ${ }^{[5]}$.

Water quality indicators in the environmental monitoring are likely to cause Chaohu Lake cyanobacteria, such as cod, COD, total nitrogen, total phosphorus and $\mathrm{pH}$, etc. It is well known that the main cause of eutrophication is the excessive nitrogen and phosphorus content, which factor caused the large area of cyanobacteria in Chaohu lake this year to attract a lot of research interest. According to Jia Xiaohui, Shi Dinji ${ }^{[6]}$ et al, the dominant species photosynthetic hypothesis.

They through the experiment explains the correlation between various water quality factors and the dominant cyanobacteria species, in Table 2. Cyanobacteria bloom is a complex ecological phenomena, the ecological system is a large number of biological and non-biological factors in the high level of integration. Many environmental factors have the effect on the growth of cyanobacteria, and in this case, it should be clear the leading factor.

Microcystis wesenbergii, Microcystis, Anabaena bloom are significantly correlated with the temperature. Can be obtained in the early spring and winter weather is cold is bloom seaweed accounted for a higher proportion, the other three predominant species. The growth of these dominant species is influenced by many environmental factors.. At the time of the change of temperature, the illumination, temperature and $\mathrm{pH}$ were the major changes of the algae growth.

Table 2. Correlation between water quality indicators and cyanobacteria species

\begin{tabular}{|c|c|c|c|c|}
\hline & $\begin{array}{c}\text { Green } \\
\text { microcapsule }\end{array}$ & $\begin{array}{c}\text { Hui } \\
\text { aeruginosa }\end{array}$ & $\begin{array}{c}\text { Microcystis } \\
\text { aeruginosa }\end{array}$ & $\begin{array}{c}\text { Patterns of } \\
\text { bloom }\end{array}$ \\
\hline Temperature $/{ }^{\circ} \mathrm{C}$ & .463 & $.8179 * *$ & $.783 * *$ & $-.889 * *$ \\
\hline $\mathrm{pH}$ & $.804 * *$ & .3924 & .498 & $.759 * *$ \\
\hline $\begin{array}{l}\text { Transparency } \\
/ \mathrm{cm}\end{array}$ & $-.736^{*}$ & -.346 & -.538 & .176 \\
\hline TN/(mg/L) & -.373 & -.3607 & $-.7168 * *$ & .586 \\
\hline $\mathrm{TP} /(\mathrm{mg} / \mathrm{L})$ & .389 & $.673 *$ & $.765 * *$ & $-.761 * *$ \\
\hline
\end{tabular}

$* *$ indicated significant correlation at.01 levels (bilaterally)

* indicates a significant correlation at 0.05 levels (bilaterally)

\section{Suggestions}

Cyanobacteria is difficult to digest, easily lead to eutrophication, causing the water body biodiversity sharply reduced, the algal blooms cause the water body anoxic, the water quality is deteriorated. It is a top priority for the treatment of cyanobacteria bloom in the way of what kind of method. First of all should be timely salvage, under high temperature in the summer bloom is easy to form, in the water will bloom salvaged put to other fish these waters is, of course, little or no floating grass plant) as fish food, make rational use of resources, or into other open land on the ground. Secondly, should fill in the pond or lake fish, with $\mathrm{H}$ square meters water filling volume of about 4500g 1400-1800 of silver carp fish tail. Can control the water bloom and can increase the fish production. It can also be evenly fertilized, fish number density of water fertilization time interval cannot be too long, the general 2-3D is appropriate, the best high temperature period is best to adhere to at least 2 days 1 . It is needed to pay attention to measure the concentration of $P$ in the body of the water, and to prevent the eutrophication of the water body from the source.

\section{References}

[1] Wang Rui, Chaohu river basin water quality assessment and water quality prediction model research: [Degree Thesis] Anhui: HeFei University of Technology, 2009

[2] Anhui Lake Environmental Protection Department of Chaohu Lake blue-green algae emergency monitoring results.www.aepb.gov.cn,2015.6.1/2015.6.3 
[3] Pearsall W H. Phytoplankton in the English Lakes II. The composition of the phytoplankton in relation to dissolved substance. Journal of Ecology,1932,20(2) : 241-262.

[4] Reynolds C S,Oliver R L,Walsby A E.Cyanobacterial dominance: the role of buoyancy regulation in dynamic lake environments.New Zealand Journal of Marine Freshwater Research, 1987, 21 (3) : 379-390.

[5] King D L.The role of carbon in eutrophication.Journal Water Pollution Control Federation, 1970, $42(12): 447-455$.

[6] Jia Xiaohui, Shi Dinji etc.. Blue green algal bloom in Chaohu lake formed to explore the reason and the dominant species photosynthetic hypothesis . Journal of ecology, 2011, 31 (11): 29682977. 